\title{
Remote Sensing Techniques in Mapping Spatial Variability of Salinity in Kano River Irrigation Project (KRIP), Nigeria
}

\author{
D. Mohammed ${ }^{1}$, M. M. Maina' ${ }^{2}$ I. Audu ${ }^{3}$, I.Y. Tudun Wada ${ }^{4}$, N. K. Nasir ${ }^{5}$ \\ ${ }^{I}$ Department of Agricultural and Bio-Environmental Engineering, Kaduna Polytechnic, Kaduna, NIGERIA. \\ ${ }^{2}$ Department of Agricultural and Environmental Engineering, Bayero University, Kano, NIGERIA. \\ ${ }^{3}$ Department of Agricultural Engineering, University of Maiduguri, NIGERIA. \\ ${ }^{4,5}$ Advance Space Technology Laboratory, National Space Research, and Development, Bayero University, Kano, NIGERIA.
}

\begin{abstract}
Salinity has become a major issue in most large scale irrigation schemes, assessing the extent of the spread has become daunting and laborious. Remote sensing techniques were used to map salinity and develop models for extracting and identifying salinity in soils. Sentinel-2B optical imaging satellite with 13 spectral bands and $10 \mathrm{~m}$ spatial resolution was used. SNAP Desktop, ERDAS Imagine, and ArcGIS 10.6 software were used as the main GIS packages for building models and running functions such as input, output, analysis, and processing. Stepwise Multiple Linear Regression (MLR) techniques were carried out for the assessment of the spatial distribution of ECe and to predict salinity level at different locations of the Kano River Irrigation Project (KRIP). Four models were developed, however, due to the lower Variance Inflation Factor (VIF), model 2 which is a combination of salinity Index and band 3 (Green band) was used in delineating the spatial extent of the salinity. Close monitoring of the salt development and application of reversal measures were recommended.
\end{abstract}

Keywords: Mapping, Irrigation, Remote Sensing, Salinity

\subsection{INTRODUCTION}

Although salt-affected soils occur in all continents and under almost all climatic conditions, the distribution, however, is relatively more extensive in the arid and semi-arid regions compared to the humid regions [1]. Statistics on the extent of salt-affected soil in the world vary. The estimate of the areas affected is close to one billion hectares, representing about $7 \%$ of the earth's continental extent. More than 120 countries are confronted with a smaller or to a greater degree with the problem of soil salinity [2]. Recent findings have shown that about 45 million ha of irrigated land which produces one-third of the world's food is salt-affected [3].

The percentage of cultivated land affected by salt comprises $19 \%$ of 2.8 billion hectares of arable land on the earth [4]. Salt affected areas on average represent $20 \%$ of the world's irrigated lands whereas, in arid and semiarid countries, it increases to more than $30 \%$. According to [5], there is risk associated with the increasing trend of the saline area of $10 \%$ per year throughout the world. It was also stated that about half of the world's irrigated area has already been damaged to some degree by water-logging and salinization and that much of the land expected to be irrigated in the future is highly vulnerable to similar damage, and at a global scale,

*Corresponding author (Tel: +234 (0) 803694 3534)

Email addresses: wadata4all@yahoo.com (D. Mohammed) mainam@buk.edu.ng (M. M. Maina), idrissaudu@gmail.com (I. Audu), iyakuba2@gmail.com (I.Y. Tudun Wada), nrsnalad@gmail.com (I.Y. Tudun Wada) at least 200000 to 300000 ha of irrigated land are lost every year due to salinization and waterlogging [6]. Many irrigation schemes around the world suffer land deterioration as a result of salinity/sodicity accumulation in agricultural soil. These also result in changes in the soil physic-chemical properties such as $\mathrm{pH}$, electrical conductivity, Sodium Adsorption Ratio, hydraulic conductivity, and soil available water. The problem manifests itself especially in regions with poorly drained soils because of the continual addition of salts with irrigation practices [1]. Salinization is becoming an increasing problem affecting agricultural production and sustainable utilization of land resources. Soil degradation due to salinity and sodicity is increasing at an alarming rate thereby adversely affecting agricultural practices [7]. In Nigeria, the problem of soil salinity in the Kano River Irrigation Project (KRIP) was well documented and reported by many researchers. It was reported by [8] that sodicity and soil fertility problems associated with sodic soils were widespread in KRIP. An ESP value as high as $40.6 \%$ and $17.5 \%$ were recorded in topsoil and sub-soil respectively. Under this situation crop yield and sustainability of production will decline unless deliberately chosen techniques oriented towards sustainability are incorporated into the crop production system. High development of sodium effect in one of the sectors due to heavy application of synthetic fertilizer on textured soil was observed by [9] and submitted that continued use of soil for irrigation activity without careful quality assessment and monitoring will give rise to 
accumulation of salts on the soils and consequently affects the crops yield potential. Signs of soil alkalinity and which led to the rise of the water table up to a depth of less than $1 \mathrm{~m}$ below ground level.

Irrigation systems have been under pressure to produce more crops with less water [11]. Various innovative practices can gain an economic advantage while also reducing environmental burdens such as water abstraction, energy use, environmental degradation, pollutants, etc. [7]. Farmers can better use technological systems already installed, adopt extra technologies, enhance their skills in soil and water management, tailor cropping patterns to lower water demand and usage, reduce agrochemical inputs, etc. to achieve sustainable agriculture.

Unsustainable pumping of groundwater resources by over-exploitation and tapping of saline aquifers, poor irrigation management, such as over-irrigation, overgrazing of the pastures and other vegetation resulting in exposure of soils to greater risks of salinization; and inadequate water quality monitoring programs to collect data from areas with potential for secondary salinization are the main causes of salt build - up in soils $[4,9]$.

Remote Sensing techniques have been widely used in mapping features on the earth's surface especially where it is practically difficult to do it manually or using conventional methods. It is practically laborious or nearly impossible to map several hectares of land within a short period, however, many studies have shown that remote sensing using satellite imagery can be used in mapping water-logging have also been reported by [10] and these have been attributed to the effects of irrigation practices large areas within a short period and with substantial precision. Monitoring and detecting of adverse effects of salt-affected soils on agricultural fields can be efficiently performed through Remote Sensing (RS) techniques [12]. Identifying areas with high salinity is of prime importance in developing a sustainable irrigation scheme. Recently, the use of Remote Sensing technologies in the prediction of soil salinity and mapping its spatial distribution in large-scales is becoming more important and easier[13].

Therefore, this work focuses on the mapping of salinity in the KRIP and its distribution in the area through the application of remote sensing and the development of different salinity models and maps that present the extent of the spread of salinity in the study area.

\subsection{MATERIALS AND METHOD \\ 2.1 Study location}

The KRIP is located between latitudes $11^{\circ} 32^{\prime} \mathrm{N}$ and $11^{\circ} 51^{\circ} \mathrm{N}$ and longitudes $8^{\circ} 20^{\circ} \mathrm{E}$ and $8^{\circ} 40^{\circ} \mathrm{E}$ within the Sudan savannah zone of Northern Nigeria. The altitude is about $440 \mathrm{~m}$ above sea level (Figure 1). The scheme was divided into two irrigation commands: Eastern and Western commands. The geology of the area consists of older granites and younger Meta sediments of Precambrian to lower Paleozoic age. The soils are mostly moderately deep to deep and well-drained with sandy loam texture at the surface and sandy clay loam textured subsoil [8].

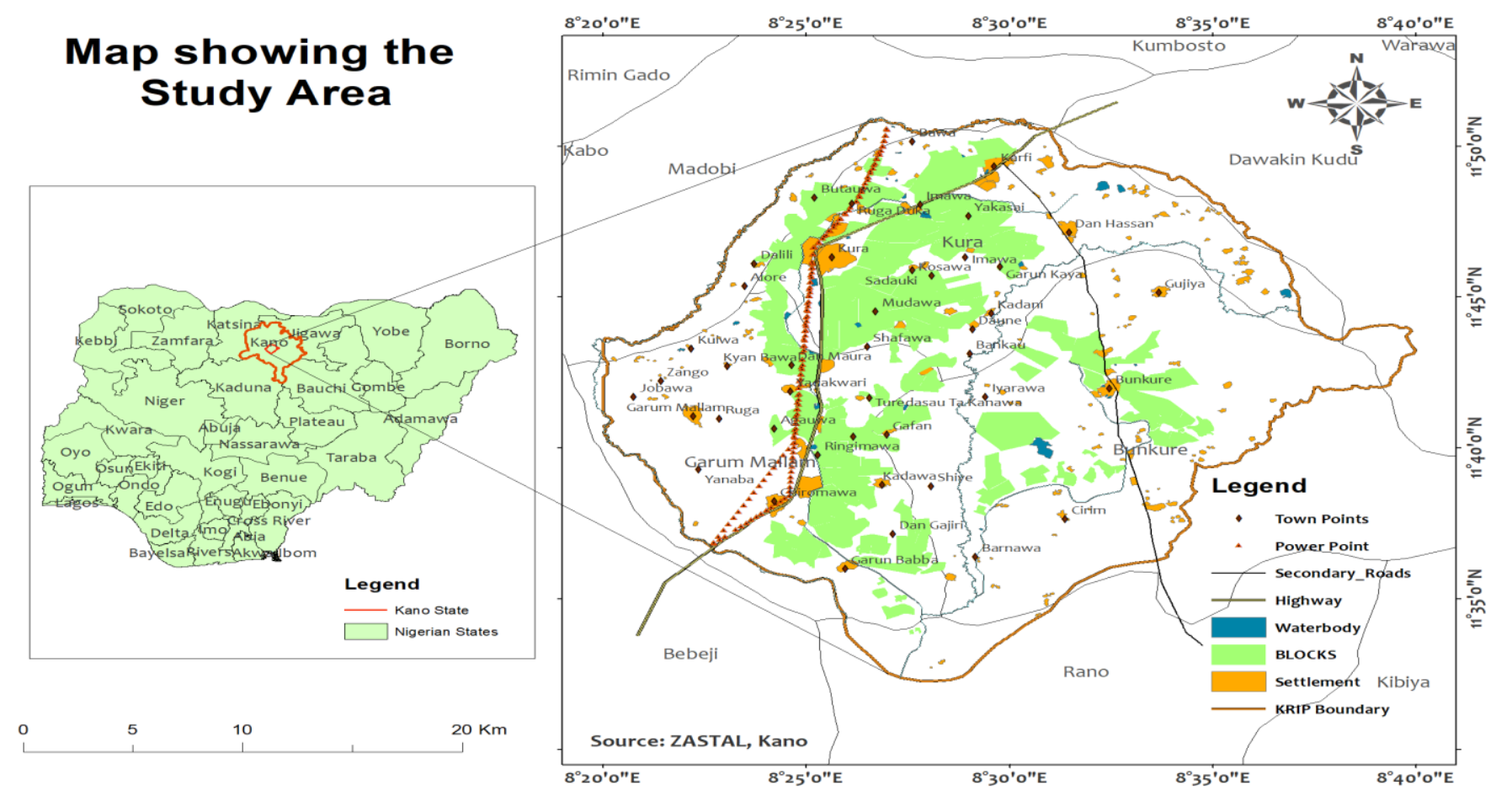

Figure 1: Map of the Study Area. (Source:[15])

The project with a total area of 62,000 ha was planned to be implemented in two phases; the Kano River
Irrigation Project Phases I and II. Phase I lies on either side of the Kano-Zaria express-way about $30 \mathrm{~km}$ south of 
Kano city. The two phases are both located at Garun Mallam, Kura, and Bunkure Local Government Areas. The project commenced operation in 1976 after it was taken over by an agency of the Federal Government under the Ministry of Water Resources: Hadejia-Jama-are River Basin Development Authority (HJRBA). The project is one of the most successful irrigation projects in Nigeria despite the setbacks. The main source of water for irrigation in the scheme is the Tiga dam which was constructed across River Kano between 1970 and 1974 [14]. The dam is the corner-stone of water resources development in Kano River valley and Hadejia in Jigawa state and the largest irrigation dam in Nigeria with a capacity of 1.968 Million $\mathrm{m}^{3}$, an embankment length of $6 \mathrm{~km}$ and a height of $48 \mathrm{~m}$ [9]. Two main canals convey water from the dam to various sectors in the scheme and each canal is $25 \mathrm{~km}$ long. One conveys water to the Kura irrigation area western command and the other to Bunkure irrigation areas eastern command.
Water is supplied by gravity through the main canal to the irrigated area and this is achieved through the distribution network, comprising of secondary canals and tertiary canals [16].

\subsection{Materials}

\subsubsection{Satellite Imagery Acquisition}

The study employed an index-based approach to using GIS with field data. The Satellite image of two different years was used to delineate salt-affected soil. Several combinations of signals received in different spectral bands were used for the development of the index (Table 1). Data from the Sentinel-2B optical imaging satellite with 13 spectral bands and $10 \mathrm{~m}$ spatial resolution was used [17]. Multi-temporal satellite images of the dry season and post-monsoon season of the year 2018, and 2019, T32PMU and T32PMT tiles were acquired and processed to identify and classify salinity presence.

Table 1: Soil Salinity Features Extracted from Sentinel-2 Satellite Data.

\begin{tabular}{lll}
\hline Index & Equation & Reference \\
\hline NDVI & $\frac{N I R-R}{R^{I R} N I R}$ & {$[18]$} \\
NDSI & $N I R+R$ & {$[17]$} \\
SAVI & $(1+L)\left(\frac{N I R-R}{N I R+R+L}\right)$ & {$[13]$} \\
BI & $\sqrt{R^{2}+N I R^{2}}$ & {$[19]$} \\
SI-1 & $\sqrt{R x N I R}$ & {$[20]$} \\
SI-2 & $\frac{S W I R 1}{N I R}$ & {$[21]$} \\
SI-3 & $\frac{B-R}{B+R}$ & {$[17]$} \\
SI-4 & $\frac{R \times N I R}{B \times R}$ & {$[18]$} \\
SI-5 & $\frac{G}{R^{2}} X G^{2}$ & {$[21]$} \\
SI-6 & $\sqrt{B \times R}$ & {$[17]$} \\
SI-7 & & {$[17]$} \\
\hline
\end{tabular}

Data for October and November 2018 and January, February, March, April, May and June 2019 were acquired. The geo-referencing of the images was done by using the Universal Transverse Mercator (UTM) coordinate system, using the World Geodetic System (WGS) 1984 datum, assigned to the North UTM zone 32.

\subsection{Methods}

\subsubsection{Image classification, modeling and mapping}

Image processing techniques were applied in the interpretation of remote sensing images and to extract as much information as possible from the images. Sentinel2 data is available in the Level-1C (L1C) processing level (Top-of-Atmosphere (TOA) reflectance in cartographic geometry), these enabled the acquisition of these images for salinity assessment. Pre-processing of L1C products was performed by scene classification and atmospheric correction, which gives L2A products. The satellite data was digitally rectified and processed using SNAP.

Preprocessing techniques such as atmospheric and radiometric corrections were applied to the multitemporal satellite images to reduce the influence of the atmosphere (Figure 2). This was also done to correct uneven sensor response over the whole image and to correct any geometric distortion due to Earth's rotation and other weather conditions. The dark object subtraction technique was used for image atmospheric correction. The method assumed the existence of zero or small surface 
reflectance. The minimum Digital Number (DN) values in the histogram from an entire scene were subtracted from all pixels. These datasets were analyzed and salt-affected areas were mapped using the geospatial approach. SNAP
Desktop, ERDAS Imagine, and the ArcGIS 10.6 were used as the main GIS packages for building models and running functions such as input, output, analysis, and processing

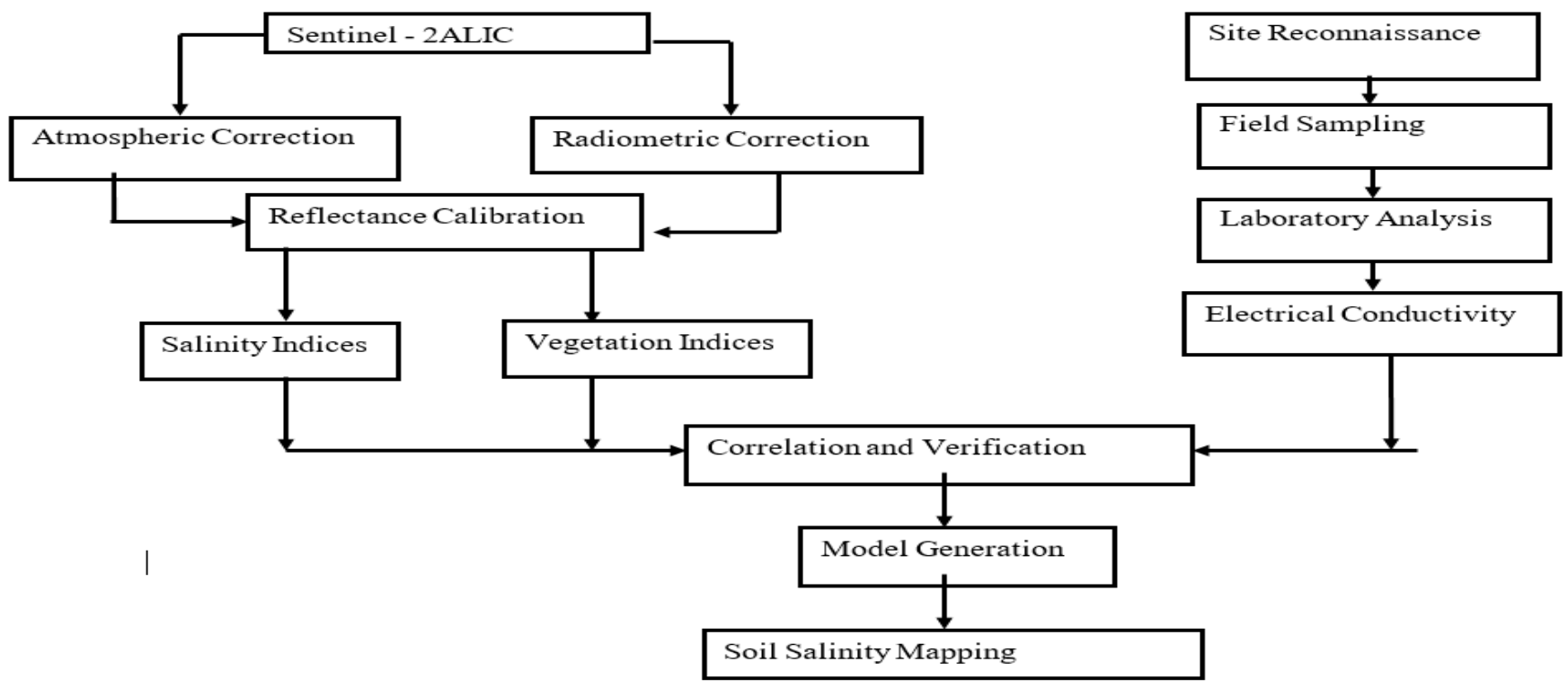

Figure 2: Flowchart for satellite image processing, model generation, and salinity mapping

\subsubsection{Model Development}

Correlation Analysis was made between the electrical conductivity of the collected field samples and band values of satellite Images to determine the relationship between these variables and to assess their efficiency in predicting soil salinity. The normality of the data was tested and found to be normally distributed as seen in Figure $3 a$ and $3 b$.

Residual plots were used to evaluate the quality of the regression. Stepwise Multiple Linear Regression
(MLR) techniques were employed in developing the models by adding or removing variables based on the tstatistics of their estimated coefficient. This was followed by the assessment of the spatial distribution of ECe to predict salinity level at different locations of KRIP based on ECe point data. These datasets were analyzed and saltaffected areas were mapped using the geospatial approach. SNAP Desktop, ERDAS Imagine, and the ArcGIS 10.6 were used as the main GIS packages for building models and running functions such as input, output, analysis, and processing.

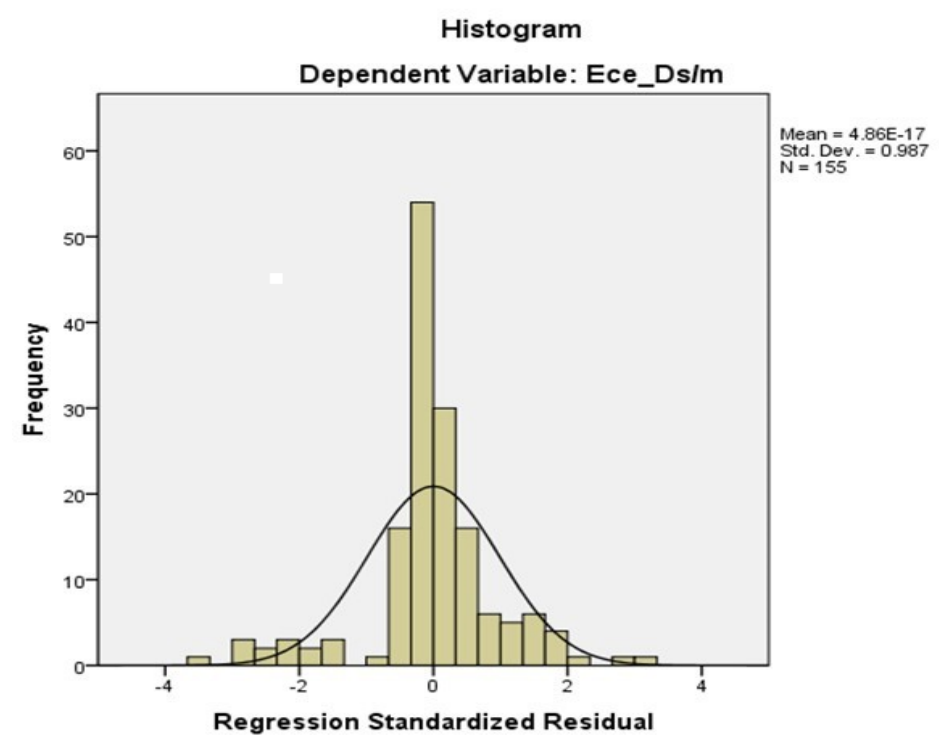

a- Normal probability plot

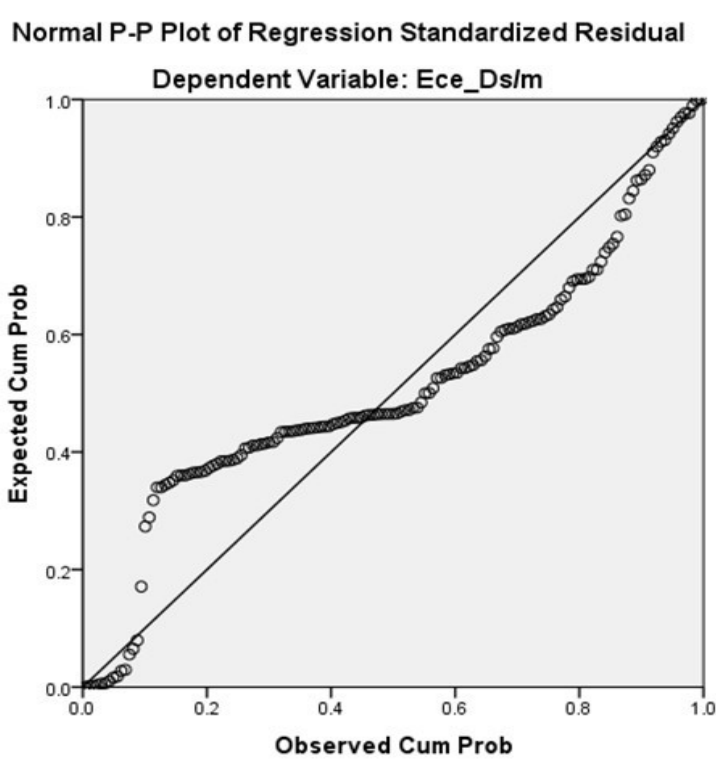

b- Normal distribution plot

Figure 3: Normal Probability Plot 


\subsection{RESULT AND DISCUSSIONS}

The results from the model generation were derived from the correlation analysis made between the electrical conductivity of the collected field samples and band values of satellite images to determine the relationship between these variables and to assess their efficiency in predicting soil salinity. Table 2 shows the coefficients which can be used to develop a multi-linear regression equation for the four models which were all tested at a 5\% level of significance. The table shows how well the model formed from the combination of salinity indices and different spectral bands derived from Sentinel data fit the sample data.

The models are summarized as follows:

Model 1: Salinity $\quad=0.041 \times B 3-0.070$
Model 2: $\quad$ Salinity $=0.033 \times \mathrm{B} 3-0.794 \times \mathrm{SI} 3+$ 0.864

Model 3: Salinity $=0.053 \times B 3-0.660 \times S I 3-$ $0.023 \times S I 5+0.857$

Model 4: Salinity $=0.062 \times B 3-0.755 \times$ SI3 $0.34 \times S I 5+0.0002 \times M S I+1.037$

From the result, it can be seen that Model 1 with $\mathrm{R}^{2}$ of 0.440 shows that, there is $44 \%$ variance in response to the measured variable (ECe) by the predictor variable (B3). The results imply that the green band (B3) is a significant factor of salinity as the model was also found to be significant with $\mathrm{F}(1,153)=120.002$, and $\mathrm{p}<.001$.

Table 2: Model summary showing adjusted $\mathrm{R}^{2}$ and Std. of error

\begin{tabular}{|c|c|c|c|c|c|c|c|c|c|}
\hline \multirow[t]{2}{*}{ Model } & \multirow[t]{2}{*}{$\mathbf{R}$} & \multirow[t]{2}{*}{$\mathbf{R}^{2}$} & \multirow{2}{*}{$\begin{array}{l}\text { Adjusted } \\
\mathbf{R}^{2}\end{array}$} & \multirow{2}{*}{$\begin{array}{l}\text { Std. Error of the } \\
\text { Estimate }\end{array}$} & \multicolumn{5}{|c|}{ Change Statistics } \\
\hline & & & & & $\begin{array}{l}\mathrm{R}^{2} \\
\text { Change }\end{array}$ & F Change & df1 & df 2 & $\begin{array}{l}\text { Sig. F } \\
\text { Change }\end{array}$ \\
\hline 1 & $.663^{\mathrm{a}}$ & .440 & .436 & 1.4546 & .440 & 120.002 & 1 & 153 & .000 \\
\hline 2 & $.683^{\mathrm{b}}$ & .467 & .460 & 1.4236 & .027 & 7.739 & 1 & 152 & .006 \\
\hline 3 & $.694^{\mathrm{c}}$ & .482 & .472 & 1.4078 & .015 & 4.415 & 1 & 151 & .037 \\
\hline 4 & $.704^{\mathrm{d}}$ & .496 & .482 & 1.3935 & .014 & 4.126 & 1 & 150 & .044 \\
\hline
\end{tabular}

Table 3: ECe Regression Model based on Spectral Bands and Salinity Indices

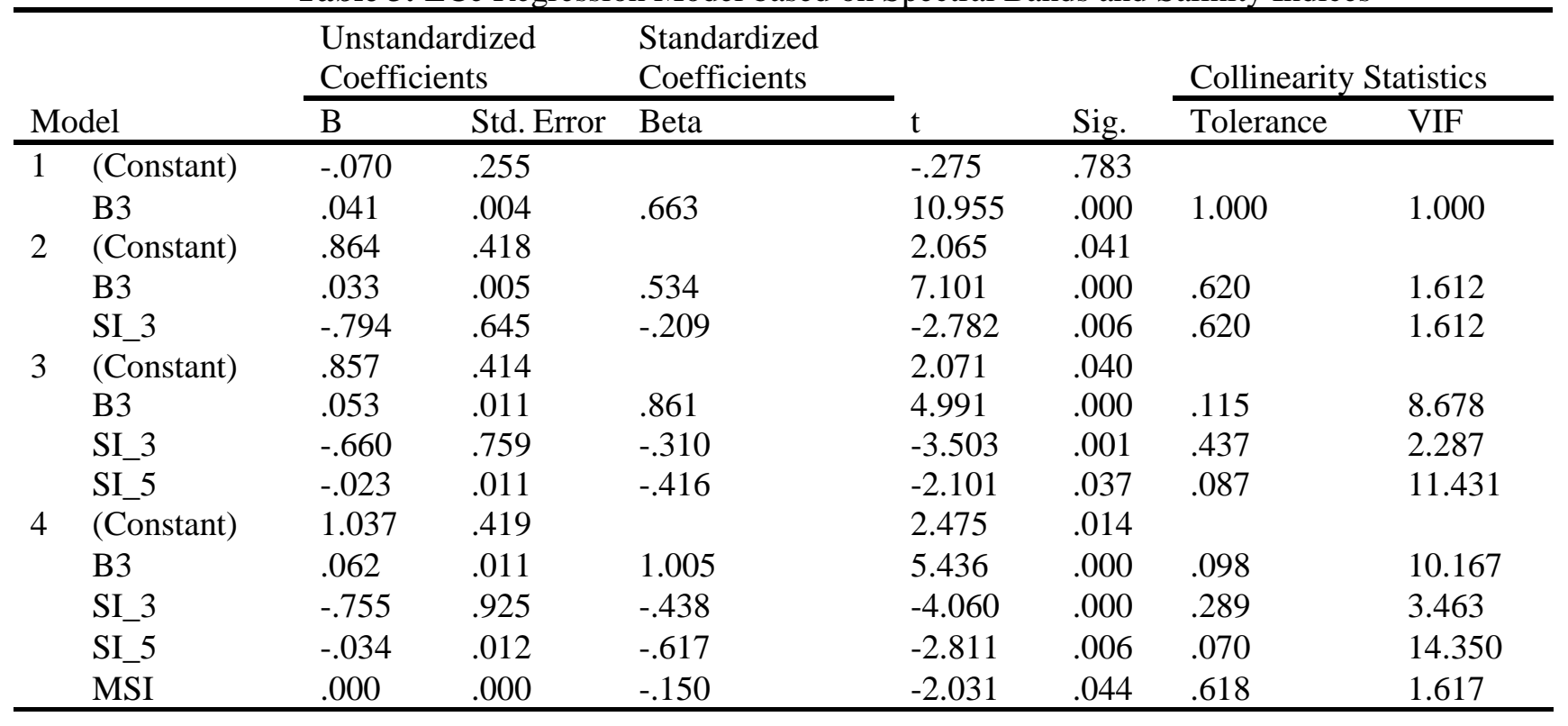

By comparing both models, it can be seen that the fourth model developed from the combination of four predictor variables (B3, SI-3, SI-5 and MSI) is a better model that fits the data than the other three models due to its higher value of $\mathrm{R}^{2}$ and lower value of the standard estimated error of 1.3935. The highest value of $R^{2}$ is an indication of a strong linear relationship between estimated and predicted ECe and this implies that approximately $50 \%$ of the variance in the ECe value could be described by the model with relatively low standard error for its variable at approximately $1.40 \%$. This is an indication that the combination of the green band (B3), SI3, SI-5 and MSI are a combination of factors that are significant in soil salinity prediction. However, due to lower VIF, model 2 which is a combination of salinity Index and band 3 was used in delineating the spatial extent of the salinity in the study area (Table 3).

The Variance Inflation Factor (VIF) for models 1, 2,3 , and 4 is $1.0,1.612,11.431$, and 14.35 respectively (Table 3.0). The higher the VIF, the less reliable is the 
regression result. For instance, the VIF value of model 4 of 14.35 implies that the coefficient is 14.35 percent bigger than what is expected if there is no issue of collinearity and this implies a very high correlation between predictors in the model which will adversely affect regression result.

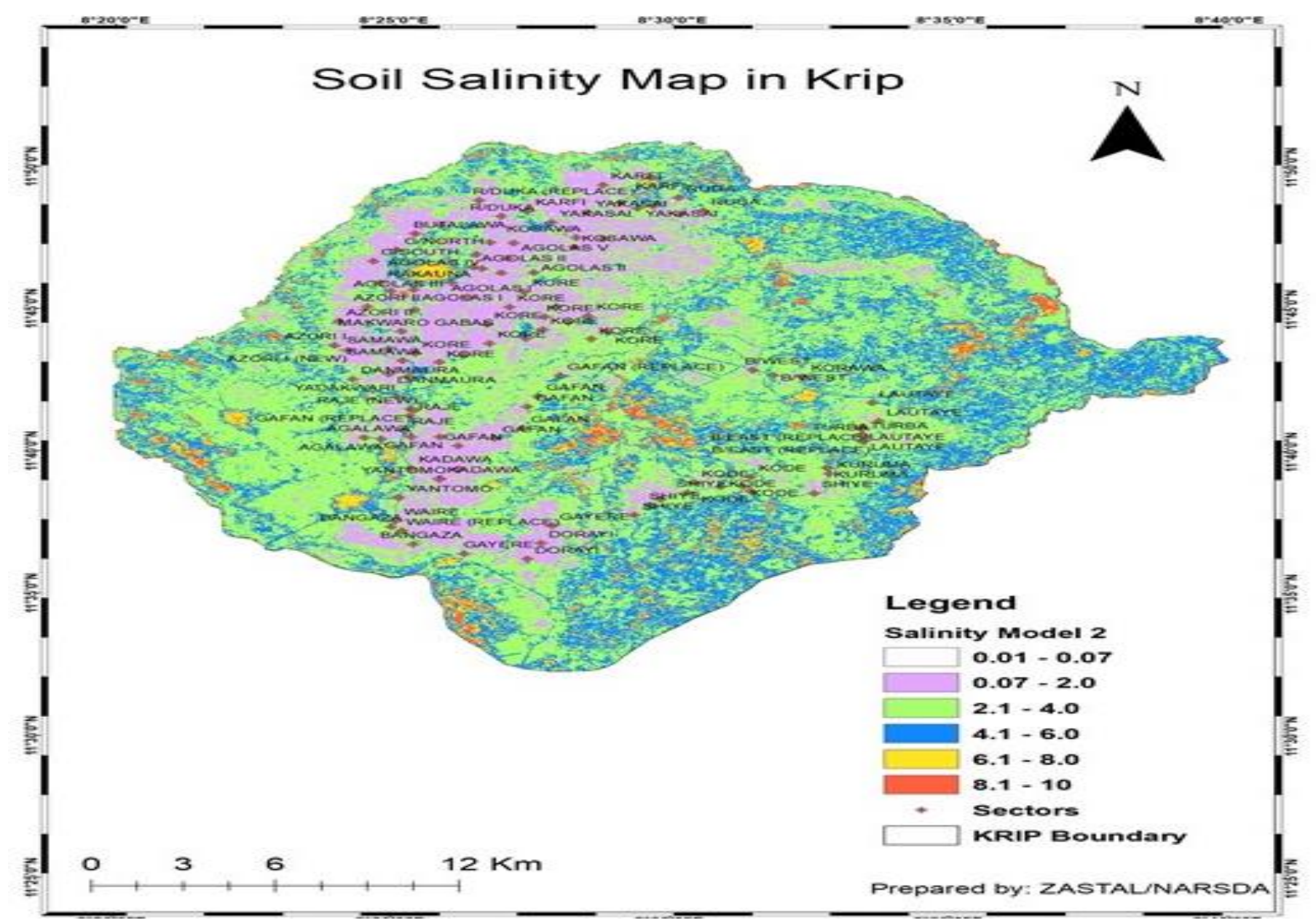

Figure 4: Salinity Map Generated from $\overline{\text { Model } 2}$

\subsection{Salinity Map}

The enhanced map of the salt-affected area in the KRIP was delineated using the selected model 2 map (Figure 4.0) which offered a lower VIF value and has a high correlation with ECe value. Six salinity classes of varying degrees were generated from the predicted salinity map. The summary for the salinity classes, salinity level, the areal extent in a hectare, and the percentage of the total area covered by each class is presented in Table 4.0.

Table 4: Areal Extent of Soil Salinity in KRIP Derived from Model 2

\begin{tabular}{llll}
\hline Salinity Level $(\mathbf{d S} / \mathbf{m})$ & Classification & Area (ha) & Area (\%) \\
\hline $\mathbf{0 . 0 1 - 0 . 0 7}(\mathbf{C 1})$ & Non-Saline & 25.29 & 0.03543 \\
$\mathbf{0 . 0 7 - 2 . 0}(\mathbf{C})$ & Non-Saline & 11385.27 & 15.9492 \\
$\mathbf{2 . 1}-\mathbf{4 . 0}(\mathbf{C 3})$ & Moderately Saline & 36248.22 & 50.7787 \\
$\mathbf{4 . 1} \mathbf{- 6 . 0}(\mathbf{C 4})$ & Very Saline & 17852.67 & 25.0091 \\
$\mathbf{6 . 1 0}-\mathbf{- 0}$ (C5) & Extremely Saline & 4641.57 & 6.50219 \\
$\mathbf{8 . 1}-\mathbf{1 0}(\mathbf{C 6})$ & Very Extremely Saline & 1231.65 & 1.72537 \\
Total & & 71384.67 & 100 \\
\hline
\end{tabular}

The soils in KRIP were approximately $50 \%$ moderately saline, $25 \%$ very saline and $6.5 \%$ are very saline. It can be seen that non-saline class $(\mathrm{C} 1$ and $\mathrm{C} 2)$ covers an area of
11400.56 ha which is about $16 \%$ of the study area supplied by the western canal. The maximum production potential of crop grown in $\mathrm{C} 1$ would be obtained because 
of the negligible effect of soil salinity [22]. However, an $\mathrm{EC}$ of $1.14 \mathrm{dS} / \mathrm{cm}$ is above the threshold value of $1.0 \mathrm{dS} / \mathrm{m}$ for onion, carrot, and bean grown in the area and these crops might experience a yield reduction above this ECe value. When employed with efficient agronomic management practices, the maximum production potential of most crops can be recorded for a value of ECe below 3 $\mathrm{dS} / \mathrm{m}[23]$. Lower salinity recorded in the irrigated area might be due to excessive leaching and other remediation measures applied in recent years.

The data has also shown that the moderately saline class (C3) with ECe of $2.1-4.0 \mathrm{dS} \mathrm{m} \mathrm{m}^{-1}$ is the dominant class as it occupies more than $50 \%$ of the study area. The class is found outside of the irrigated area and covers an area of 36248.22 ha. The salinity might be possibly due to leached salt conveyed and deposited in the areas surrounding the cropped field by runoff water. The very saline class $(\mathrm{C} 4)$ with ECe of $4.1-6.0 \mathrm{dS} \mathrm{m}{ }^{-1}$ occupies an area of 17852.67 ha which represents about $25 \%$ of the study area mostly located near waterways and drainages. This might be due to leaching of accumulated salts outside the irrigated area and human activities associated with the use of detergents as the farmers used to wash their clothes using detergents, and seepage of saline water as it drains into the waterways from the irrigated farms. Extremely saline class (C5 and C6) covering an area of 5873.22 ha accounted for approximately $8 \%$ of the study area and is found in settlements where the drainage water from the irrigated area and saline areas surrounding the cropped areas is conveyed. The higher value recorded in the settlements could also be attributed to damaged roads that have led to waterlogging of many areas in the settlements, seepage of saline water from adjacent cropped areas, and evaporation of stagnated water from these areas.

\subsection{CONCLUSION}

This study employed the use of remote sensing techniques to map salinity in KRIP and from the result obtained, salinity in KRIP were moderate, however, there are places with severe cases. The study also showed the capability of remote sensing to delineate areas affected by salinity from the normal areas which will be useful in monitoring the spread of the salinity. The low salinity recorded in the irrigated area is attributed to leaching and other remediation techniques applied over the years. The higher value recorded in the settlements has been attributed to damaged roads that have led to water-logging of many areas in the settlements, seepage of saline water from adjacent cropped areas, and evaporation of stagnated water from waterlogged areas.

\section{ACKNOWLEDGMENT}

This to acknowledged funding of the project from the Transforming Irrigation Management In Nigerian (TRIMING) under the Federal Ministry of Water
Resources-Nigeria. Also the support from the Laboratory Centre for Dryland Agriculture (CDA), Bayero University, Kano for various chemical analyses.

\section{REFERENCES}

[1] Salih, S. A. R., Elsheik, M. A. M.and Aydrous, A. E. "Determination of the Effect of Gypsum and Irrigation Water in Reclamation of Sodic Soils in South Khartoum," (2015), 55-57.

[2] Govender, M., Chetty, K. and Bulcock, H. "A review of hyperspectral remote sensing and its application in vegetation and water resource studies," Water SA, 33(2), (2007), 145-152.

[3] Khadim, F. K., Su, H., Xu, L. and Tian, J. "Soil salinity mapping in Everglades National Park using remote sensing techniques and vegetation salt tolerance," Physics and Chemistry of the Earth, Parts A/B/C, 110 (2019), 31-50.

[4] Marcos, M., Sharifi, H., Grattan, S. R. and Linquist, B. A. "Spatio-temporal salinity dynamics and yield response of rice in water-seeded rice fields," Agricultural Water Management, 195 (2018), 37-46.

[5] Zare, M., Ordookhani, K., Emadi, A., \& Azarpanah, A Relationship Between Soil Exchangeable Sodium Percentage and Soil Sodium Adsorption Ratio in Marvdasht Plain, International Journal of Advanced Biological and Biomedical Research, 2(12), (2014), 2934-2939.

[6] Mattamana B. A., Varghese, S. and Paul, K. "Irrigation System Assessment- Farmer's and Manager's view," International Journal Engineering Science and Innovative Technology, 2(2), (2013), 148-159.

[7] Kaledhonkar, M. J., Sharma, D. R., Tyagi, N. K., Kumar, A. and Van Der Zee, S. E. A. T. M. "Modeling for conjunctive use irrigation planning in sodic groundwater areas," Agricultural Water Management, 107, (2012), 14-22.

[8] Jibrin, J. M., Abubakar, S. Z. and Suleiman, A. "Soil fertility status of the Kano River irrigation project area in the Sudan Savanna of Nigeria," Journal of Applied Sciences, 8(4), (2008), 692696.

[9] Maina, M. M., Amin, M. S. M., Aimrun, W. and Sani, I. "Soil salinity assessment of Kadawa Irrigation of the Kano River Irrigation Project (KRIP)," Journal of Food, Agriculture \& Environment, 10(3\&4), (2012), 1028-1034.

[10] Simon, E. "Environmental impact assessment, Kano River irrigation project (Phase I) extension, Nigeria," IAHS Publications-Series of Proceedings and Reports-Intern Assoc Hydrological Sciences, 240 (1997), 185-192.

[11] Maina, M. M. Amin, M. S. M. Aimrun, W. and Asha, T. S. "Evaluation of Different ET 0 
Calculation Methods : A Case Study in Kano State , Nigeria," Philipine Agricultural Science, 95(4), (2012), 378-382.

[12] Yildirim Gorji, A. T., Hamzehpour, N. and Sertel, E. "Comparison of Different Soil Salinity Indices Derived From SENTINEL-2A IMAGES," in International Symposium on Applied Geoinformatics, 1(1), 2019.

[13] Taghadosi, M. M., Hasanlou, M. and Eftekhari, K. "Retrieval of soil salinity from Sentinel-2 multispectral imagery," European Journal of Remote Sensing, 52(1), (2019),138-154.

[14] Mohammed, D., Ibrahim, H. A. and Abdulsalam, A. "Variabilty of Irrigation Water Quality in Kano River Irrigation Project," Journal of Res. Natl. Dev. Dep. Marit. Management, 12(2), (2015), 337-343.

[15] Zonal Advance Space Technology Laboratory, "Map of Kano River Irrigation Project," Kano, 2019.

[16] Sangari, D. U. "An Evaluation of Water and Land Uses in the Kano River Project, Phase I, Kano State," 11(2), (2006), 105-111.

[17] Taghadosi, M. M., Hasanlou, M. and Eftekhari, K. "Retrieval of soil salinity from Sentinel-2 multispectral imagery," European Journal of Remote Sensing, 52(1), (2019), 138-154.

[18] Azabdaftari A. and Sunar, F. "Soil salinity mapping using multitemporal landsat data," The International Archives of the Photogrammetry, Remote Sensing and Spatial Information Sciences, 7, (2016), 3-9.

[19] Khan, N. M., Rastoskuev, V. V., Shalina, E. V and Sato, Y. "Mapping Salt-affected Soils Using Remote Sensing Indicators - A Simple Approach With the Use of GIS IDRISI," 22nd Asian conference on remote sensing, (2001), 5-9.

[20] Dehni, A. and Lounis, M. "Remote Sensing Techniques for Salt Affected Soil Mapping: Application to the Oran Region of Algeria," Procedia Engineering, 33, (2012), 188-198.

[21] Khan. S. and Abba . A., "Remote Sensing Based Modelling Applications in Land and Water Management:," in Using Remote Sensing for Appraisal of Irrigated Soil Salinity. MODSIM 2007., (2007).

[22] Mandal, A. K. "Mapping and characterization of salt-affected and waterlogged soils in the Gangetic plain of central Haryana (India) for reclamation and management," Cogent Geoscience, 2(1), (2016),1-17.

[23] Ayers, R.S. and Westcots, D.W. "Water quality for Agriculture" Irrigation and Drainage Paper 29. Food and Agriculture Organization of the United Nation, Rome, (1976). 